Article

\title{
Comparative Mitogenomic Analysis of Two Cuckoo Bees (Apoidea: Anthophila: Megachilidae) with Phylogenetic Implications
}

\author{
Huanhuan $\mathrm{Lu}^{1}{ }^{1}$, Bo He $^{2}$, Youjin Hao ${ }^{1}$, Zeyang Zhou ${ }^{1}$, Chengyong Su ${ }^{2, *}$ and Dunyuan Huang ${ }^{1, *(1)}$ \\ 1 Chongqing Key Laboratory of Vector Insects, College of Life Sciences, Chongqing Normal University, \\ Chongqing 401331, China; 2019110513046@stu.cqnu.edu.cn (H.L.); 20130100@cqnu.edu.cn (Y.H.); \\ zyzhou@cqnu.edu.cn (Z.Z.) \\ 2 College of Life Sciences, Anhui Normal University, Wuhu 241000, China; hebo90@ahnu.edu.cn \\ * Correspondence: 20170054@cqnu.edu.cn (D.H.); sucy@mail.xzcit.cn (C.S.)
}

Citation: Lu, H.; He, B.; Hao, Y.; Zhou, Z.; Su, C.; Huang, D.

Comparative Mitogenomic Analysis of Two Cuckoo Bees (Apoidea: Anthophila: Megachilidae) with Phylogenetic Implications. Insects 2021, 12, 29. https://doi.org/ $10.3390 /$ insects 12010029

Received: 30 November 2020 Accepted: 3 January 2021 Published: 5 January 2021

Publisher's Note: MDPI stays neutral with regard to jurisdictional clai$\mathrm{ms}$ in published maps and institutional affiliations.

Copyright: (C) 2021 by the authors. Licensee MDPI, Basel, Switzerland. This article is an open access article distributed under the terms and conditions of the Creative Commons Attribution (CC BY) license (https:// creativecommons.org/licenses/by/ $4.0 /)$.
Simple Summary: Megachilidae plays an important role in natural and agricultural ecosystems. There is uncertainty in the phylogenetic relationship among tribes of Megachilidae. Due to the lack of basic analysis of the mitogenomic structure of the cuckoo bees (cleptoparasitic bees) of the Megachilidae, the risk of insect cleptoparasitism in the Megachilidae is not fully understood. To further provide a new perspective on the phylogenetic relationship of Megachilidae and enrich the basic theory of cleptoparasitic controls, two mitogenomes of cuckoo bees (Coelioxys fenestrata and Euaspis polynesia) were sequenced and analyzed. Different mitogenomic structures and base compositions were found between two cuckoo bees based on comparative analyses of general characteristics of the mitochondrial, noncoding region and gene rearrangement pattern. In addition, the phylogenetic results strongly supported that the tribe-level relationship of Megachilidae was Osmiini + (Anthidiini + Megachilini). Our findings clarified the phylogenetic position among tribes from the mitogenome level so as to provide a further basis to study the evolution of Megachilidae.

Abstract: Bees (Hymenoptera, Apoidea and Anthophila) are distributed worldwide and considered the primary pollinators of angiosperm. Megachilidae is one of the largest families of Anthophila. In this study, two complete mitogenomes of cuckoo bees in Megachilidae, namely Coelioxys fenestrata and Euaspis polynesia, were amplified and sequenced, with a length of 17,004 bp (C. fenestrata) and $17,682 \mathrm{bp}$ (E. polynesia). The obtained results show that 37 mitogenomic genes and one putative control region were conserved within Hymenoptera. Truncated stop codon T was found in the cox 3 gene of E. polynesia. The secondary structure of small $(\mathrm{rrnS})$ and large $(\mathrm{rrnL})$ rRNA subunits contained three domains (28 helices) and five domains (44 helices) conserved within Hymenoptera, respectively. Compared with ancestral gene order, gene rearrangement events included local inversion and gene shuffling. In order to reveal the phylogenetic position of cuckoo bees, we performed phylogenetic analysis. The results supported that all families of Anthophila were monophyletic, the tribe-level relationship of Megachilidae was Osmiini + (Anthidiini + Megachilini) and Coelioxys fenestrata was clustered to the Megachile genus, which was more closely related to Megachile sculpturalis and Megachile strupigera than Euaspis polynesia.

Keywords: Megachilidae; mitochondrial genome; genome structure; phylogenetic analysis; gene rearrangement

\section{Introduction}

Megachilidae, one of the largest families in Anthophila, comprises about 4000 species and is distributed almost all over the world [1-3]. It is characterized by most female bees using their upper jaws to cut leaves as nesting materials [4,5]. The extant Megachilidae, most widely accepted, is divided into two subfamilies and seven tribes [1]. Megachilidae 
can be further classified as pollinating bees with abdominal brushes and cuckoo bees (cleptoparasitic bees) without abdominal brushes [1,6]. Pollinating bees play an important role in nature. For example, Megachile rotundata (Fabricius, 1793) has been promoted in all parts of the world as an alfalfa (Medicago sativa L.) pollinator [7], Osmia lignaria (Say, 1837) has a better pollination effect than Apis mellifera (Linnaeus, 1758) (Hymenoptera: Apidae) [8] and Megachilid bees have been found all over the world except Antarctica [6]. Therefore, as pollinators, they play an irreplaceable role in maintaining the ecosystem and increasing the yield of many crops $[5,6,9]$.

Megachilidae contains many cuckoo bees that attack pollinators of other tribe-genera of the same family $[1,6]$. Cleptoparasitism means that cleptoparasitic bees lay their eggs on pollen clusters or egg chambers made by pollinating bees, and their larvae grow on the food provided by the host. Compared with C. fenestrata, the female bees of E. polynesia sneak into the closed nest of the host for cleptoparasitic activities, which causes the loss of a large number of pollinators [5]. At the same time, they are easy to catch and have a wide range of hosts. Cleptoparasitism of insects of the same family is a rare phenomenon. For instance, the Euaspis genus (Gerstacker, 1858) cleptoparasitizes the genera Lithurgus (Berthold, 1827) and Megachile (Latreille, 1802) [10,11], and the Coelioxys genus (Latreille, 1809) is cleptoparasitic in all genera of the tribe Megachilini [12,13]. In addition, some studies suggested that all tribes of the Megachilinae subfamily are monophyletic, and the tribe-level phylogenetic relationships were proposed as Anthidiini + Megachilini + Osmiini $[14,15]$. However, other studies suggested that some species of Megachilini originated from Osmiini, Osmiini are considered paraphyletic $[1,16,17]$.

Mitochondrion is a semiautonomous organelle, in which oxidation is performed and energy is released for eukaryotes. A typical insect mitochondrial genome (mitogenome) contains 13 protein-coding genes (PCGs) encoding protein subunits involved in oxidative phosphorylation, 22 tRNAs (trnS and trnL have two isomers) and two rRNAs ( $r r n L$ and $r r n S$ ) [18]. In addition, the insect mitogenome has a control region (CR) [19] that regulates replication and transcription. Because of distinctive properties such as maternal inheritance, strict orthologous genes and a low rate of recombination [20,21], insect mitogenomes have been extensively applied for intraordinal phylogen [22-24], phylogeography [25] and molecular evolution $[26,27]$ as a molecular marker.

Currently, only complete mitogenomes of three pollinating bees of Megachilidae have been released in the National Center for Biotechnology Information (NCBI) [28-30]. In this study, we sequence the mitogenomes of the two cuckoo bees and analyze the differences of mitogenomes between the two species from their general characteristics, genome structure, special structure of the noncoding region and gene rearrangement pattern. At the same time, we also perform phylogenetic analysis in order to clarify the interspecific relationship of Megachilidae and the phylogeny of Anthophila for short- and long-tongued bees. Overall, our results provide a basis for further phylogenetic analysis of cuckoo bees in the Megachilidae family.

\section{Materials and Methods}

\subsection{Sampling and DNA Extraction}

Adult stages of $C$. fenestrate and E. polynesia were collected by the sweeping net method in the Jinggang Mountains, Jiangxi Province, China, in October, 2019. The latitude and longitude of the collection sites are $26^{\circ} 28^{\prime} 16.5^{\prime \prime} \mathrm{N}$ and $114^{\circ} 12^{\prime} 33.8^{\prime \prime} \mathrm{E}$, identified by Dr. Ze-qing Niu (Institute of Zoology, Chinese Academy of Sciences) based on morphological characteristics. The voucher specimens (No. C. fenestrate-2019-2T-1 and No. E. polynesia2019-2E-1) were stored at $-20^{\circ} \mathrm{C}$ (College of Life Sciences, Chongqing Normal University). Total genomic DNA of one adult per species was extracted with the Tissue DNA Kit (Omega Biotek, Norcross, GA, USA) following the manufacturer's instructions. 


\subsection{Sequencing and Assembly}

The mitochondrial DNA was fragmented to an average size of $450 \mathrm{bp}$ using the Covaris M220 system (Covaris, Woburn, MA, USA) and used for the library preparation. The library was constructed using the Illumina TruSeq ${ }^{\mathrm{TM}}$ Nano DNA Sample Prep Kit (Illumina, San Diego, CA, USA) and sequenced on the platform of Illumina Hiseq 4000 (Illumina, San Diego, CA, USA). Before assembly, raw reads were filtered, and quality was assessed using Fast-QC (http:/ / www.bioinformatics.babraham.ac.uk/projects/fastqc). High-quality clean reads were used for the subsequent analysis based on Q20 ( $>95 \%)$ and Q30 (>90\%). The complete nucleic acid sequence was assembled by MITObim v1.7 [31] based on the reference sequence of Osmia excavata (Alfken, 1903) [30] (GenBank accession number: KX494106).

\subsection{Bioinformatic Analysis}

The tRNAs and their secondary structures were identified using the MITOS web server [32], ARWEN [33], tRNAscan-SE Online Search Server [34] and by manual proofreading. Boundaries of PCGs were determined by the positions of tRNAs. PCGs were predicted using the Open Reading Frames (ORFs) finder implemented in Unipro UGENE v34 [35] and confirmed by the MITOS web server. Similarly, positions of rRNAs and the CR were identified based on the boundaries of tRNAs and homology comparison [28,29]. The secondary structure of rRNAs ( $r r n L$ and $r r n S$ ) was deduced from the known models of other Hymenoptera insects [36-39]. Helix numbering was determined to be in accordance with the regulations of the comparative RNA web (CRW) [40]. Moreover, the secondary structure was folded through RNA Structure v5.6 [41] and identified by manual proofreading. Finally, the comparable gene identical map was visualized by the BLAST Ring Image Generator (BRIG) v0.95 [42].

Base composition, AT or GC skews, codon usage and relative synonymous codon usage (RSCU) were analyzed by PhyloSuite v1.2.2 [43]. DnaSP (v6.12.03) was applied to estimate the nucleotide diversity $(\mathrm{Pi})$ between the mitogenomes of $C$. fenestrata/M. sculpturalis (Smith, 1853) and E. polynesia/M. strupigera (Cockerell, 1922) [44]. The tandem repeats in the intergenic spacers were predicted using the Tandem Repeats Finder program (http://tandem.bu.edu/trf/trf.basic.submit.html). The CR was searched through the MISA online web server (MIcroSAtellite identification tool) [45].

\subsection{Phylogeny Analysis}

To explore their phylogenetic relationships, 27 mitogenomes of Anthophila and two outgroup species, Abispa ephippium (Fabricius, 1775) (Hymenoptera: Vespidae) and Philanthus triangulum (Fabricius, 1775) (Hymenoptera: Crabronidae), were used (Table S1). Multiple sequence alignment of 13 PCGs, 22 tRNAs and two rRNAs was performed by Mafft v7.310 in PhyloSuite (alignment strategy: L-INS-i). Individual alignments were then concatenated using PhyloSuite, and the poorly aligned and high divergence regions were removed by Gblocks $0.91 \mathrm{~b}$ in PhyloSuite. In addition, the potential index of substitution saturation (Iss) of each nucleic acid sequence was calculated by DAMBE v7.2.1 [46]. To test the influence of the 3rd codon and gene combination types on the subsequent phylogenetic analysis, four datasets were constructed: (1) the 1st and 2nd codon positions of 13 PCGs and 22 tRNAs $\left(\mathrm{PCG}_{12}+\mathrm{T}\right)$; (2) all three codon positions of PCGs and tRNAs $\left(\mathrm{PCG}_{123}+\mathrm{T}\right)$; (3) the $\mathrm{PCG}_{12}+\mathrm{T}$ and two rRNAs $\left(\mathrm{PCG}_{12}+\mathrm{T}+\mathrm{R}\right)$; (4) total gene sequences $\left(\mathrm{PCG}_{123}+\mathrm{T}+\mathrm{R}\right)$. Partition-Finder (v2.1.1) was used to infer the best evolutionary model [47]. Finally, the evolutionary processes of gene arrangement in two cuckoo bees were estimated by the Common-interval Rearrangement Explorer (CREx) [48].

The BI and ML trees were constructed by MrBayes v3.2.6 and IQ-TREE v1.6.8 within PhyloSuite, respectively. The ML analysis was conducted under the parameters of an ultrafast bootstrap with 1000 replicates. The BI analysis was conducted with four Markov Chain Monte Carlo (MCMC) chains of 1 million generations twice, which was sampled every one thousand steps and discarded the first $25 \%$ of the generations as burn-in. When 
the average standard deviation of the split frequency was less than 0.01 , the potential scaling reduction factor (PSRF) was close to 1 , and when the estimated sample size (ESS) was greater than 200, the MCMC analysis was stopped. The ESS value was viewed through Tracer v1.7.1 [49]. Phylogenetic trees were visualized and edited by iTOL [50].

\section{Results and Discussion}

\subsection{General Features of the Mitogenome of C. fenestrata and E. polynesia}

The complete mitogenome of C. fenestrata (GeneBank accession number: MT898425) and E. polynesia (MT909816) is $17,704 \mathrm{bp}$ and 17,682 bp, respectively (Table S1). Each contains 37 typical mitogenomic genes [29,51]. Most are concentrated at the J strand (9 PCGs, 13 tRNAs of C. fenestrata and 12 tRNAs of E. polynesia). Other genes (4 PCGs, 2 rRNAs, 9 tRNAs of $C$. fenestrata and 10 tRNAs of E. polynesia) are concentrated at the $\mathrm{N}$ strand (Figure 1, Table S2). For C. fenestrata, the total nucleic acid sequence of all PCGs is $11,151 \mathrm{bp}$ with $79.6 \%$ AT content, and the length/AT content of tRNAs and rRNAs is $1423 \mathrm{bp} / 85.7 \%$ and $2064 \mathrm{bp} / 84.9 \%$, respectively (Table S3). Except for the control region, 18 intergenic regions were found in the mitogenome of $C$. fenestrata (390 bp totally) and E. polynesia (1032 bp totally). Nine and ten overlapping regions were found in the mitogenome of C. fenestrata (39 bp totally) and E. polynesia (58 bp totally), respectively (Table S2).

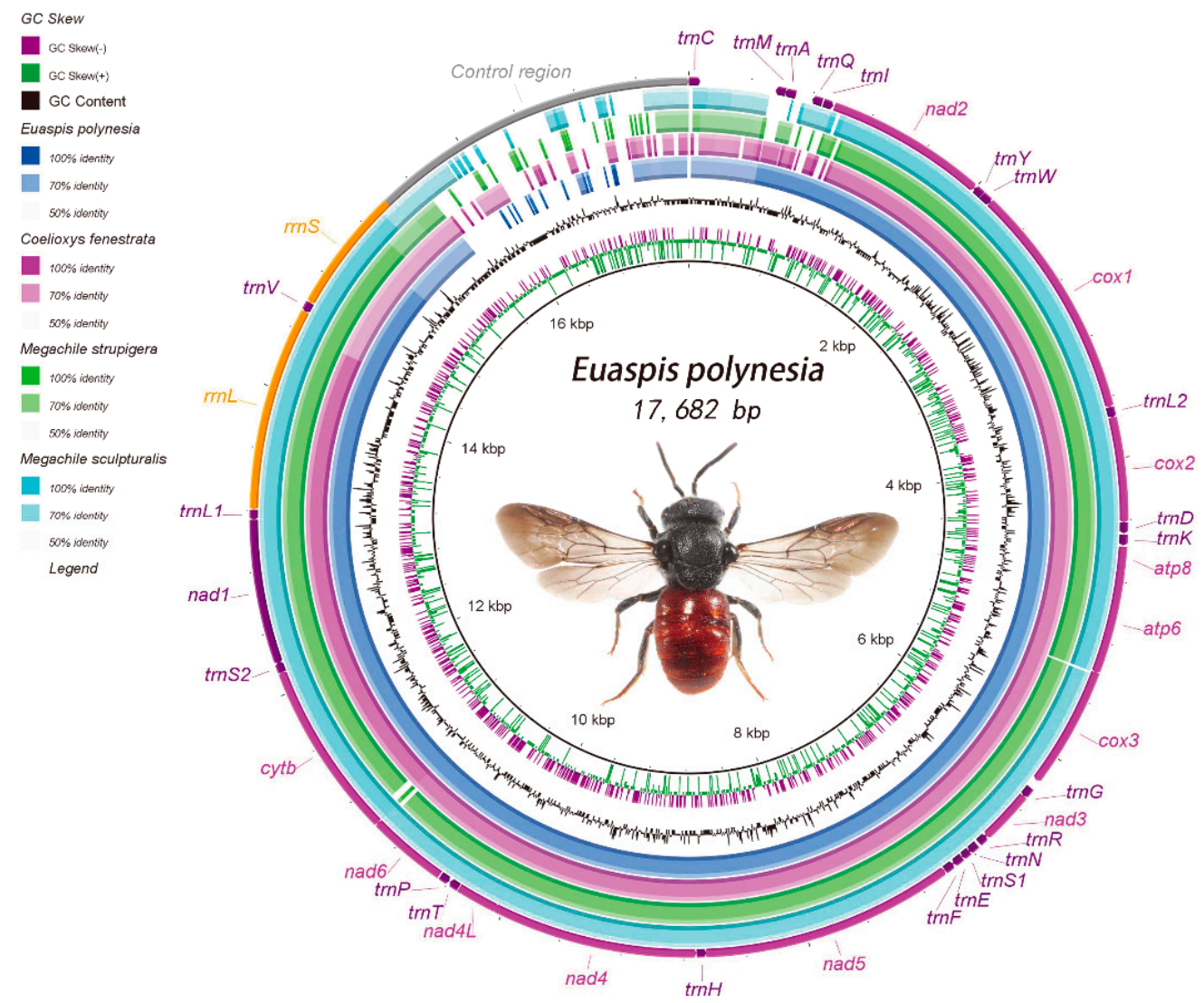

Figure 1. Circular map of the mitogenome of Megachilidae. The different colors represent the nucleotide identity using the mitogenome of O. excavata as a reference (Acc. No.: KX494106) [30].

Compared with three publicly released mitogenomes of Megachilidae (O. excavate, M. sculpturalis and M. strupigera), C. fenestrata has the lowest AT content (82.9\%), and E. polynesia has the highest AT content (85.9\%) (Table S1). From the bias skew, the AT and GC skews in both mitogenomes are similar to those of other Megachilidae species: more A/C than T/G in the J strand [52], positive AT skew and negative GC skew (Table S1). The mitogenome of Megachilidae was visualized so that a circular map was generated (Figure 1). 
The result showed that the locations of some tRNAs (e.g., $\operatorname{trn} E, \operatorname{trn} F, \operatorname{trnK}, \operatorname{trnL2}, \operatorname{trnP})$ are highly conservative. For PCGs, genes $\operatorname{cox} 1, \operatorname{cox} 2$ and $\operatorname{cox} 3$ are more conservative than genes nad2, nad4L, cytb and nad6 (Figure 1).

\subsection{Genome Structure}

\subsubsection{Protein-Coding Genes}

In both newly sequenced mitogenomes, the usage patterns of the start codon and the stop codon are similar (Table S2). For instance, the most frequently used start codon by PCGs is ATN. Although most PCGs use TAA or TAG as the stop codon, a truncated stop codon $\mathrm{T}$ was found in the cox3 gene of E. polynesia. Truncated stop codons are commonly observed in many mitogenomes of Hymenoptera insects and are expected to be completed via the post-transcriptional polyadenylation process [53].

The result of RSCU analyses showed that the frequency of $\mathrm{A} / \mathrm{T}$ is higher than that of $\mathrm{G} / \mathrm{C}$ in the third codon position (Figure 2). For instance, the third codon position among the six most commonly used codons (TTA, TCA, CGA, ACA, GTT and TCT) in the mitogenome of $C$. fenestrata is $A$ or $T$. On the contrary, codons rich in $C$ or $\mathrm{G}$ are rarely used in the mitogenome of $C$. fenestrata, such as CCG, GCG, GGC and CGC. This phenomenon is more obvious in the mitogenome of E. polynesia because codon CGC and GCG are not used at all (Table S4).

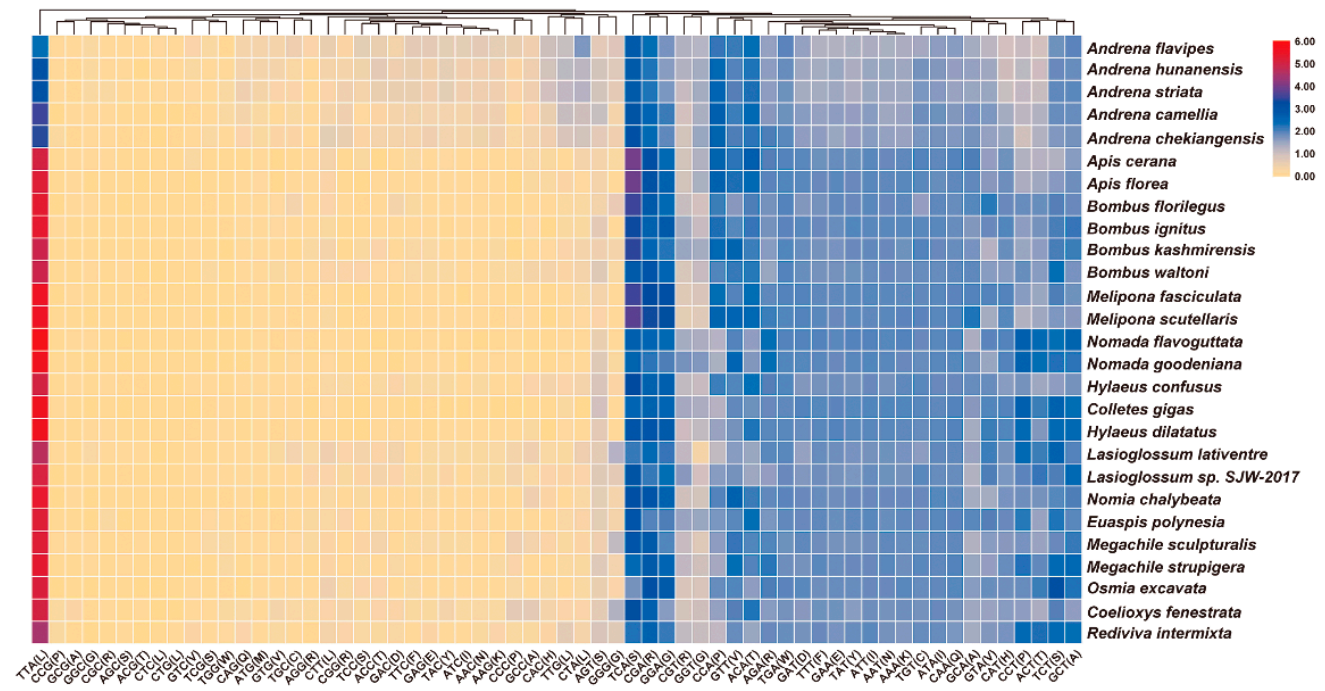

Figure 2. The relative synonymous codon usage (RSCU) of protein-coding genes (PCGs) in the mitogenomes of Anthophila. The $x$-axis and $y$-axis represent the codon type and species name, respectively. The legend in the upper-right corner represents the usage frequency of synonymous codons.

\subsubsection{Transfer RNA Genes}

Twenty-two typical tRNAs were identified in both mitogenomes (Figure 3). Most of them could be folded into a typical clover-leaf secondary structure except for trnS1. This phenomenon often occurs in the mitogenomes of Hymenopteran insects [36,37,54]. The secondary structure of tRNAs consists of "four arms" and "four loops." Among them, the amino-acid arm (14 bp) and anticodon loop (7 bp) are highly conserved, which is very common for metazoans $[38,39]$. The extra loop determines the molecular weight of tRNAs. Moreover, the secondary structures of tRNAs contain some unconventional base pairs such as G-U specific matches and A-C or G-U mismatches, which were also found in the mitogenomes of other Hymenoptera insects [36-39]. Finally, these unconventional structures will be corrected in the subsequent editing stage [55] or represent unusual pairings [40]. 

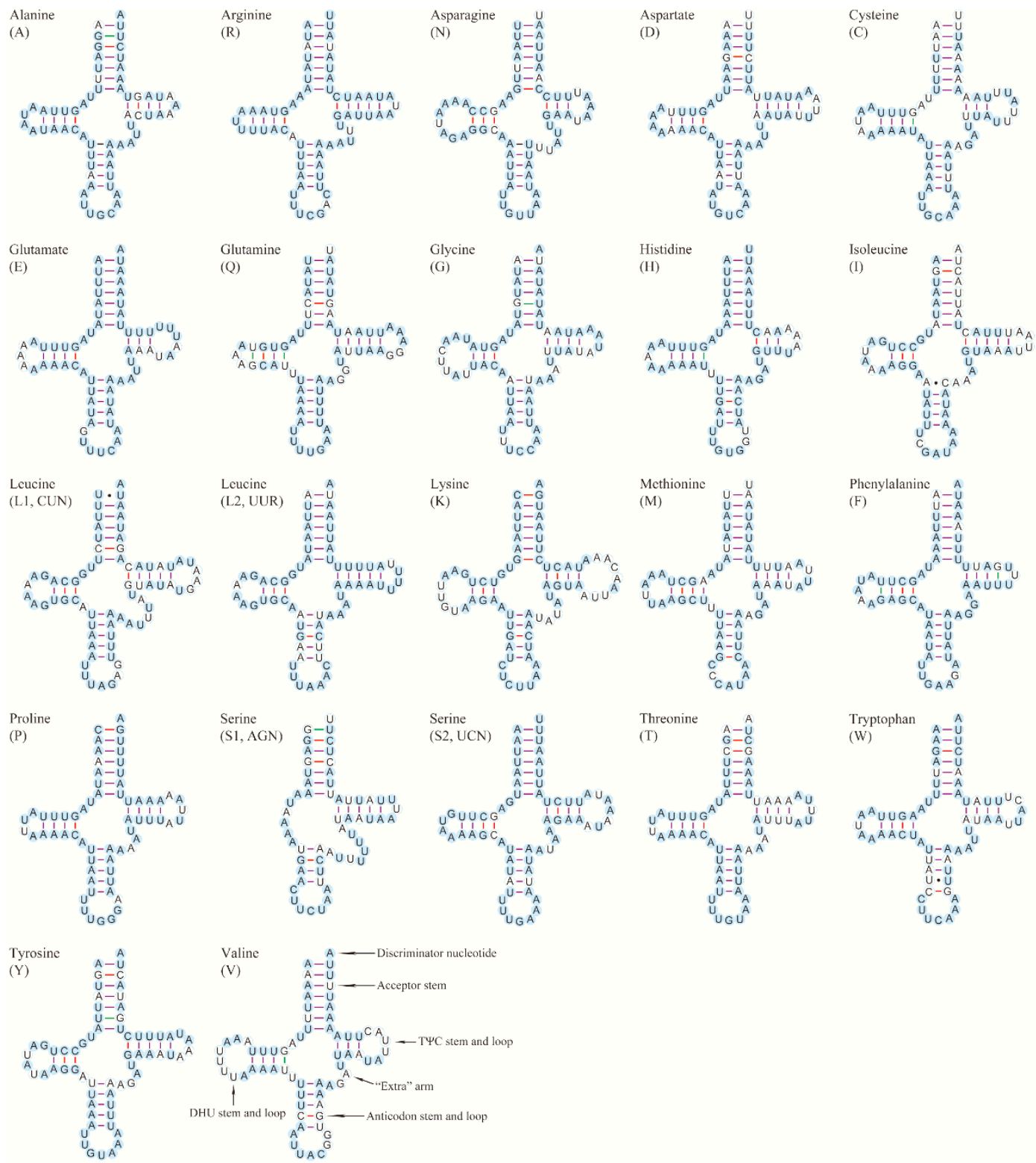

Figure 3. Secondary structures of tRNAs in the mitogenome of $C$. fenestrata. The filled circle represents the nucleotide conserved. The bonds of A-U, G-U, G-C and mismatches are marked with a purple line, green line, red line and solid dots, respectively.

\subsubsection{Ribosomal RNA Genes}

Compared with the mitogenome of E. polynesia, the sequence alignments of $r r n L$ of C. fenestrata spans 1342 sites including 1026 conserved sites $(76.45 \%)$ and 361 variable sites (23.55\%) (Figure S1). Furthermore, the sequence alignments of $r m S$ spans 805 sites including 615 conserved sites $(76.40 \%)$ and 190 variable sites $(23.60 \%)$ (Figure S2). Conserved nucleotides were dispersed in each rRNA sequence.

The secondary structure of $r r n S$ and $r r n L$ contains three domains (28 helices) and five domains (44 helices), respectively. Among the five domains of $r r n L$, Domain III does not exist, which is a typical feature of arthropods [40]. The three domains of $r r n S$ have always been controversial. For example, the nonconservation of helix H47 leads to the variousness of the secondary structure of Domain I in insects [56]. Although helix H673 forms a relatively conservative structure in Hymenoptera [36-39], it shows diverse secondary structure models in other insect species $[57,58]$. 


\subsubsection{Noncoding Regions}

The noncoding regions of the mitogenome consist of the intergenic spacers (IGSs) and the control region (CR). The IGSs of the mitogenome of E. polynesia (469 bp) are located between genes trnM and trnR with two repeat regions (RRs) (Figure 4a). RR1 consists of three tandem repeats ( $44 \mathrm{bp}$ totally) with insertions and deletions. RR2 is also composed of three tandem repeats ( $43 \mathrm{bp}$ totally) with base mutations (Figure $4 \mathrm{a}$ ). The IGSs of the mitogenome of $C$. fenestrat $a$ are located between genes nad 6 and $c y t b$ and also contain a region (228 bp) with three tandem repeats (Figure $4 \mathrm{~b}$ ). Except for nucleotide deletions, no mutations and insertions were found. Further analysis revealed that the IGSs of the mitogenome of $C$. fenestrata form a secondary structure (Figure $4 b$ ). Similar repeat sequences and complementary secondary structures were also found in IGSs of the mitogenomes of other species $[59,60]$. The secondary structure formed by repetitive sequences is usually related to the starting of the replication of the mitogenome [61,62].

$\mathbf{a}$

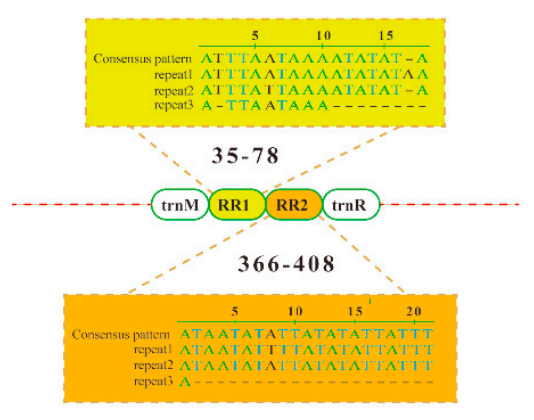

b

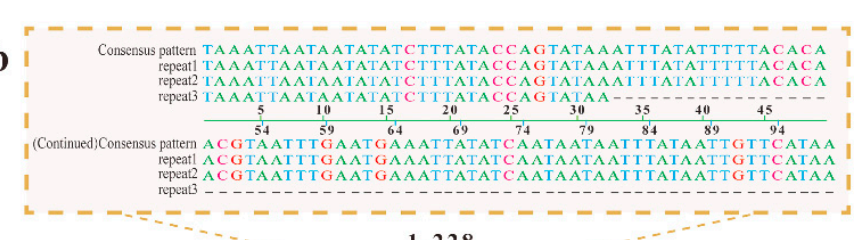

$1-228$
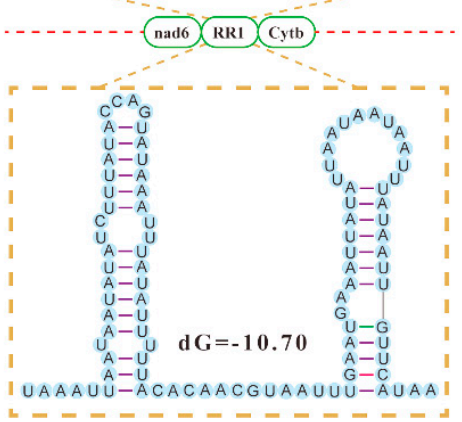

Figure 4. Repetitive sequences and secondary structure of intergenic spacers (IGSs) of the mitogenome of E. polynesia (a) and $C$. fenestrata $(\mathbf{b})$. The numbers above/below the boxes denote the positions of the RRs within the IGSs.

The AT content in the CR is $90 \%$ for C. fenestrata (2015 bp) and $91.4 \%$ for E. polynesia, (2128 bp), respectively, which was higher than in other regions. In the CR of the mitogenome of $C$. fenestrata, AT and GC skews are -0.020 and -0.420 , respectively. Furthermore, for E. polynesia, A/G are more abundant than $\mathrm{T} / \mathrm{C}$ (AT skew $=-0.082$, GC skew $=0.402$ ). Further analysis showed that there were many repetitive sequences similar to microsatellites in the CR (Table S5). Microsatellite-like sequences among individuals in different geographical locations were proposed as a new marker to study the phylogenetic geography of Hymenoptera [63].

\subsubsection{Gene Rearrangement}

Gene rearrangement can be divided into remote inversion, local inversion, translocation and gene shuffling [52]. Local inversion accounts for a large proportion of gene order patterns in the mitogenomes of Hymenoptera [64]. In the mitogenomes of Megachilidae, gene shuffling (trnW-trnC-trnY, nad6-cytb-trnS2, trnG-nad3-trnA-trnR, trnV-rrnS-trnI and $\operatorname{trnK} / \operatorname{trn} D$ ) and a local inversion of $\operatorname{trnR}$ were found (Figure 5). Similarity analysis showed that the gene order of the mitogenomes of Megachilidae was significantly different (Table S6). Compared with the ancestral gene order of insect mitogenomes, the transformation process from the ancestor to E. polynesia and C. fenestrata has undergone rearrangement and transposition events (Figure 5 and Figure S3). These patterns were also found in the other 18 species. Gene rearrangements occur in both tRNAs and rRNAs except for PCGs. Rearrangements are concentrated in some regions of tRNAs, including trnI-trnQ-trnM, 
trnW-trnC-trnY, and trnA-trnR-trnN-trnS1-trnE-trnF, which is also considered a common rearrangement region of other Hymenoptera [65,66]. In addition, another gene rearrangement cluster, rrnL-rrnS-trnV, was observed in E. polynesia, Colletes gigas (Cockerell, 1918) (Hymenoptera: Colletidae) and Hylaeus dilatatus (Kirby, 1802) (Hymenoptera: Colletidae) (Figure 5).

\begin{tabular}{|c|c|c|c|}
\hline \multirow{8}{*}{ Apidae } & \multirow{3}{*}{ Bombus } & Ancestral type & 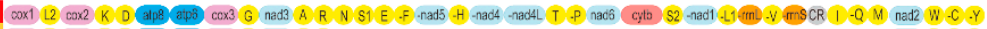 \\
\hline & & Bombus ignitus & 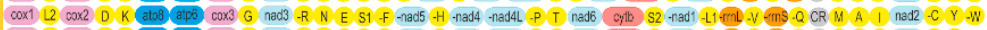 \\
\hline & & Bombus kashmirensis & 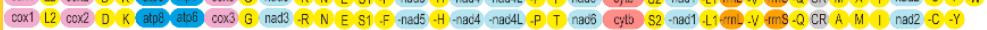 \\
\hline & Meling & Melipona & 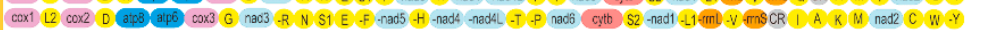 \\
\hline & & Melipona scutellaris & 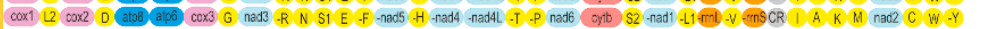 \\
\hline & Apis & Apis cerana & 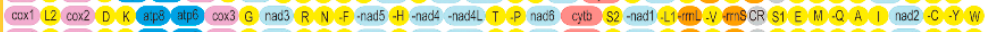 \\
\hline & & pis florea & 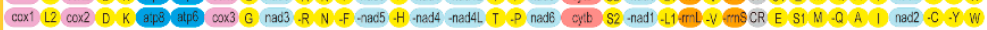 \\
\hline & Nom & goodeniana & 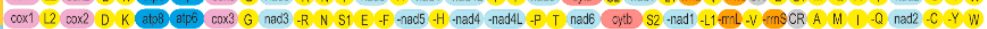 \\
\hline & Megachile & $\begin{array}{l}\text { Megachile sculpturalis } \\
\text { Megachile strupigera }\end{array}$ & 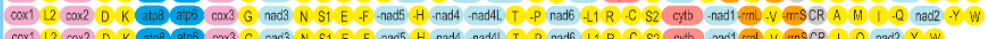 \\
\hline egachilidae & & $\begin{array}{l}\text { Megachile strupigera } \\
\text { Coelioxys fenestrata }\end{array}$ & 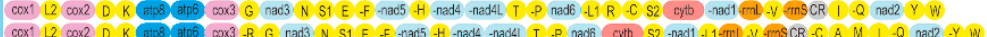 \\
\hline & Euaspis & $\begin{array}{l}\text { Euetioxys Tonesestrita } \\
\text { Euaspis polynesia }\end{array}$ & 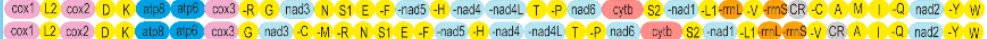 \\
\hline & Osmia & Osmia exca & 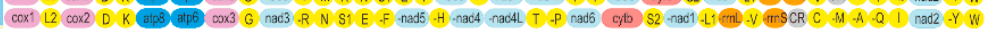 \\
\hline lae & Nom & Nomia chalybeata & 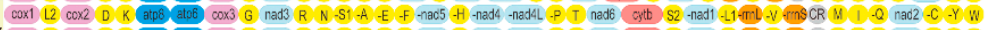 \\
\hline & & Lasioglossum sp.S. & 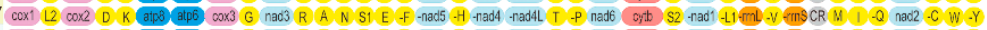 \\
\hline Andrenidae & Andrena & Andrena c. & 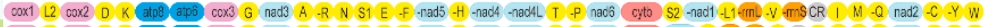 \\
\hline Colletidae & & Collet & 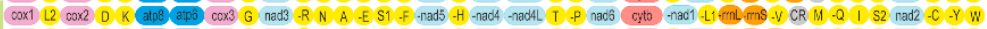 \\
\hline & & & 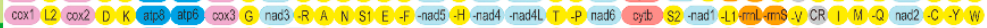 \\
\hline Idae & & Rediviva intermixta & 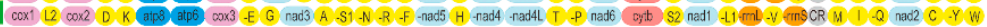 \\
\hline
\end{tabular}

Figure 5. Gene arrangement of the mitogenomes. "-" indicates that the gene is encoded by the N strand; otherwise, they are encoded by the J strand. The three columns to the left of the gene rearrangement are the family, genus, and species of bees.

\subsection{Nucleotide Diversity}

The results showed that the Pi value ranges from 0.100 to 0.473 in two mitogenomes of C. fenestrata (Smith, 1873) and E. polynesia (Vachal, 1903) (Figure 6, Table S7). The diversity of genes nad6 $(\mathrm{Pi}=0.402)$, nad2 $(\mathrm{Pi}=0.398)$, atp8 $(\mathrm{Pi}=0.389)$ and nad4L $(\mathrm{Pi}=0.385)$ was higher, whereas that of cox1 $(\mathrm{Pi}=0.178)$, $\operatorname{rrnL}(\mathrm{Pi}=0.210)$ and $r r n S(\mathrm{Pi}=0.211)$ was lower (Table S7: Pi of Gene). To validate the reliability and versatility, further analysis was conducted for genes in the mitogenomes of C. fenestrata/M. strupigera (Cockerell, 1922) and E. polynesia/M. sculpturalis (Smith, 1853). Similar results were found in the pairwise comparison of C. fenestrate (Smith, 1873) and E. polynesia (Vachal, 1903) (Figure 6). All results support that $\operatorname{cox} 1$ is the least variable and can be a potential marker for species identification [67,68]. However, hypervariable genes (nad6, nad2, atp8 and nad4L) are suitable for studying the phylogenetic relationship of species-level Megachilidae [69].

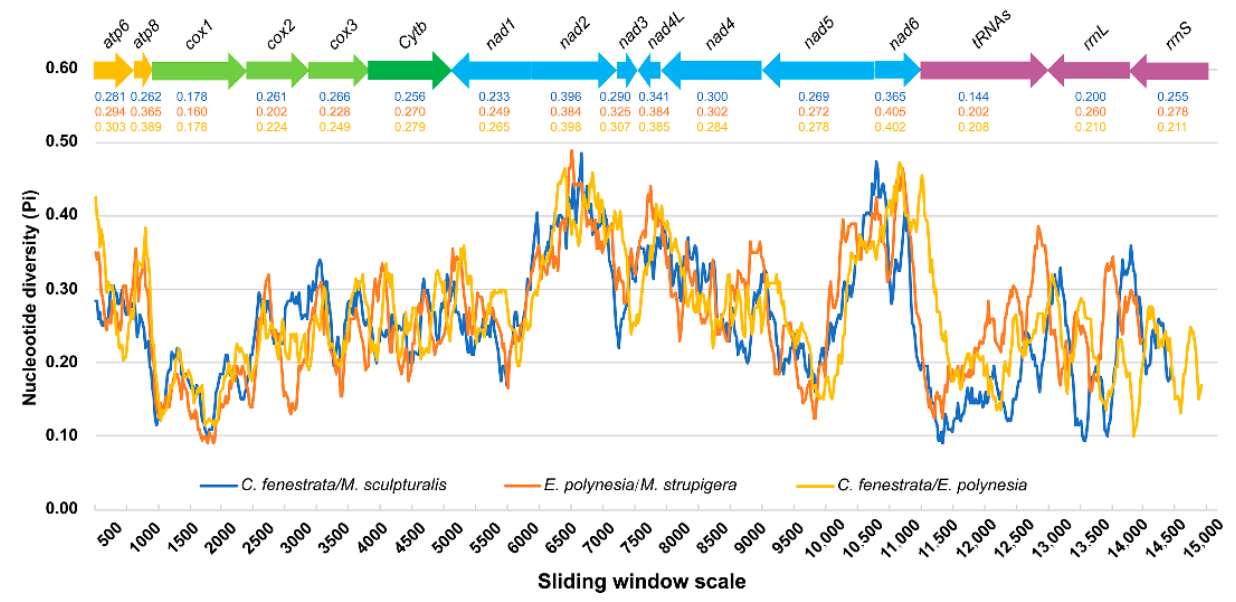

Figure 6. Nucleotide diversity of the mitogenome of E. polynesia and C. fenestrata. Sequence alignments of 13 PCGs, 2 rRNAs and 22 tRNAs were analyzed by sliding window (window size $=200 \mathrm{bp}$, step size $=20 \mathrm{bp}$ ). The polyline represents the value of nucleotide diversity. The arrow represents the direction of gene coding, with the gene name above it and the average nucleotide diversity value of the gene below. 


\subsection{Phylogenetic Analysis}

\subsubsection{Substitution Saturation Tests}

Substitution saturation of nucleic acid sequences was performed (Table S8). For datasets not filtered by Gblocks, the substitution saturation index (Iss) for both the first codon and all codons of PCGs is less than the index of Iss.cSym but larger than Iss.cAsym. This result suggested that unfiltered datasets may produce some noises for subsequent phylogenetic analysis. It was worth noting that the index Iss of the third codon of all PCGs, rRNAs and tRNAs are larger than the index of Iss.cSym and Iss.cAsym, suggesting that they cannot provide useful information for the phylogenetic analysis. Furthermore, the filtered datasets, except for the third codon and rRNAs, were helpful to explore phylogenetic relationships.

\subsubsection{Topology Consistency Analysis}

To test the influence of different genes on the phylogenetic analysis, four datasets $\left(\mathrm{PCG}_{12}+\mathrm{T}, \mathrm{PCG}_{12}+\mathrm{T}+\mathrm{R}, \mathrm{PCG}_{123}+\mathrm{T}\right.$ and $\mathrm{PCG}_{123}+\mathrm{T}+\mathrm{R}$ ) were used (Figure S4). The ML and BI trees are shown in Figure S5. Except for dataset $P_{C G_{12}}+\mathrm{T}+\mathrm{R}$, the other three datasets produced a consistent topology in both ML and BI analysis (Figure 7). In this study, when the third codons of PCGs were included, the rRNAs data would reduce the node support (e.g., $\mathrm{PCG}_{123}+\mathrm{T}+\mathrm{R}$ and $\mathrm{PCG}_{123}+\mathrm{T}$ ) and had negative effects on both topology and node support when the datasets excluded the third codons (e.g., $\mathrm{PCG}_{12}+\mathrm{T}+\mathrm{R}$ and $\mathrm{PCG}_{12}+\mathrm{T}$ ). Interestingly, the negative effect of rRNA genes can be reversed by including the third codon of PCGs. Previous studies also showed that nucleotide sequences of tRNAs could ameliorate node support and the stability of topology [70,71]. In addition, some studies proposed that excluding the third codon can produce a more consistent topology [72], but our results supported that the third codon positions of all PCGs were useful for inferring phylogenetic relationships among taxa that diverged relatively recently [73-75].

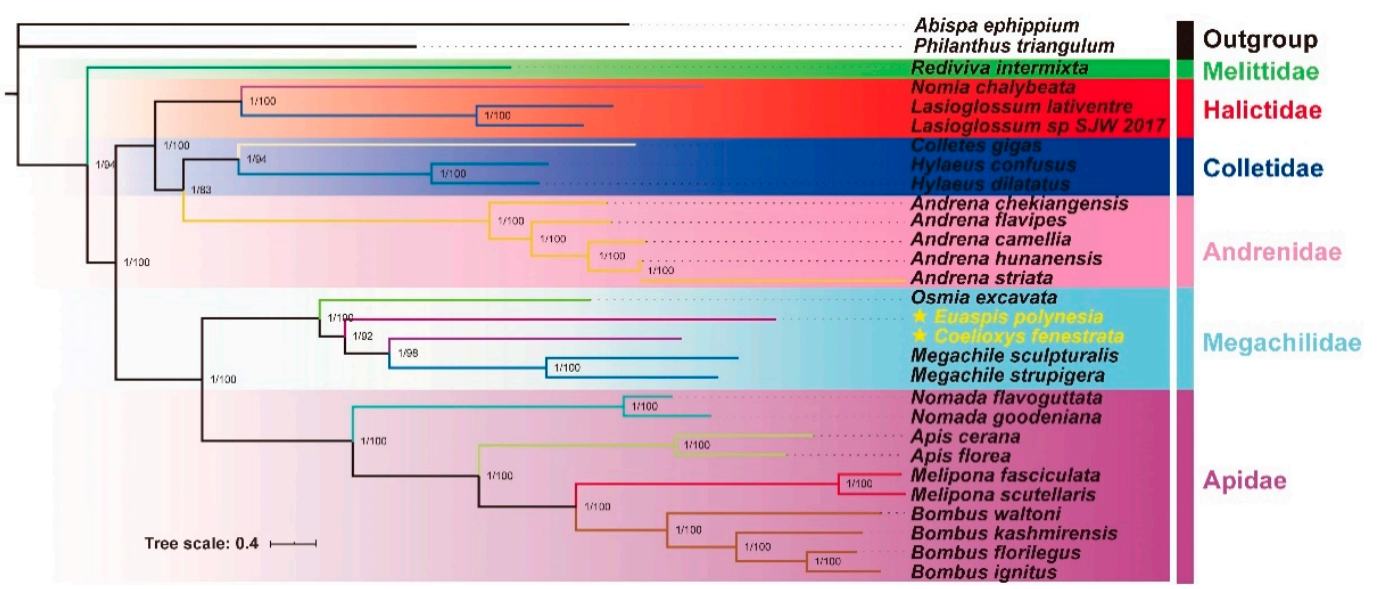

Figure 7. The consensus phylogenetic tree of 27 Anthophila species. The support values of the corresponding nodes are represented by Arabic numerals, the left side of "/" is bootstraps of BI, and the right side of "/" is the posterior probability of ML.

\subsubsection{Phylogenetic Relationship}

The phylogenetic analysis based on mitogenomes of 27 species showed that Melittidae, Halictidae, Colletidae, Andrenidae, Megachilidae and Apidae families were a monophyletic group with high support (Figure 7). Species in each family were clustered into one group, except for the Melittidae family, in which only one mitogenome was included. Melittidae was identified as a sister of other families. In related studies, the above conclusion supported the discussion that the Melittidae were the sister group of other bee families of Zheng et al. [30], and supported the family-level hierarchical phylogeny of Anthophila of He et al. [52] and Aydemir et al. [76]. The phylogenetic relationship of Anthophila was (Apidae + Megachilidae) (long-tongued bees) and (Andrenidae + (Halictidae + Colletidae) 
(short-tongued bees). The analysis results do not support that the Melittidae belong to the short-tongued bees' group [18,30] or the three-way split evolution among Melittidae, Andrenidae and the remaining families [77]. Our results were strongly supported by large-scale morphological data [2], multigene tandem sequence [78-80], transcriptome [81] and genome $[82,83]$.

In this study, two cuckoo bees were used in the phylogenetic analysis and the results indicated that the O. excavate (tribe Osmiini) was a sister group of other species of Megachilidae (Figure 7). Previous phylogenetic analysis based on mitogenomes also revealed that tribe Osmiini was the sister group of other species of Megachilidae [30,52]. Coelioxys fenestrata, M. sculpturalis and M. strupigera formed a group (tribe Megachilini), which was close to E. polynesia (tribe Anthidiini). The tribe-level phylogenetic relationship of Megachilidae was Osmiini + (Anthidiini + Megachilini). Although this study is inconsistent with some previous studies [14-17], the monophyly of each tribe is highly supported in this study. The phylogenetic status of Megachilidae is established with higher supports on each node, which indicates that its phylogenetic relationship is reliable. For the origin of cleptoparasitism within Megachilidae, Michener proposed there were 10 origins [1], whereas Litman et al. thought it should be five or six origins $[84,85]$ because the monophylic status of Coelioxys and Radoszkowskiana is controversial. Additionally, this cleptoparasitic behavior evolved from a closed nest to an open nest. Therefore, it was considered a unidirectional evolution [84]. In this study, genera Coelioxys and Euaspis, which contain C. fenestrata and E. polynesia, respectively, were regarded as independent origins, according to Litman's opinions about the evolution of cleptoparasitism [84]. Only the mitogenomes of five species are included in this study, and more species will be needed to analyze the phylogenetic relationships of Megachilidae.

\section{Conclusions}

The complete mitogenome sequences of $C$. fenestrata and E. polynesia are provided. Comparative genomics and phylogenetic analysis are carried out among the mitogenomes of two cuckoo bees. The results show that a truncated stop codon $\mathrm{T}$ is found in cox3 of E. polynesia, which is expected to be completed via the post-transcriptional polyadenylation process. The secondary structures of tRNAs contain unconventional base pairs, which will be corrected in the subsequent editing stage. Gene rearrangement events include local inversion and gene shuffling. The phylogenetic results support that $C$. fenestrata was more closely related to M. sculpturalis and M. strupigera than E. polynesia. The tribe-level relationship of Megachilidae is Osmiini + (Anthidiini + Megachilini). The phylogenetic status of the cleptoparasitism of Megachilidae was more clearly understood. In addition, regarding the sister relationship between Melittidae and other bee families, the other families were divided into two groups: (Apidae + Megachilidae) (long-tongued bees) and (Andrenidae $+($ Halictidae + Colletidae) $)$ (short-tongued bees). In future studies, more mitogenomes of other species are needed to further explore the phylogenetic relationship of Megachilidae.

Supplementary Materials: The following are available online at https://www.mdpi.com/2075 $-4450 / 12 / 1 / 29 / s 1$, Figure S1: Predicted secondary structure of the $r r n L$ in the mitogenome of C. fenestrata. Figure S2: Predicted secondary structure of the rrnS in the mitogenome of C. fenestrata. Figure S3: Heuristically exploring the mitochondrial rearrangements of C. fenestrata and E. polynesia. Figure S4: Summary of the major clades recovered by different datasets and analytical approaches. Figure S5: Phylogenetic relationship inference using different datasets and analytical approaches. Table S1: Summary of mitogenome data used in this study. Table S2: Comparison of the annotated mitochondrial genomes of $C$. fenestrata and E. polynesia. Table S3: Nucleotide composition of the mitogenome of C. fenestrata and E. polynesia. Table S4: The relative synonymous codon usage (RSCU) of PCGs in Anthophila mitogenomes. Table S5: Microsatellite-like identification in the putative control region of the mitogenome of C. fenestrata and E. polynesia. Table S6: Pairwise common intervals comparison of mitochondrial gene orders among Anthophila species, based on the order of all tested genes. Table S7: Sliding window analyses of the mitogenome of C. fenestrata, M. sculpturalis, 
E. Polynesia and M. strupigera. Table S8: Saturation substitution tests for PCGs, rRNAs and tRNAs of the mitogenomes of Anthophila.

Author Contributions: Conceptualization, H.L., B.H., Z.Z. and D.H.; data curation, H.L., B.H., Y.H. and D.H.; formal analysis, H.L. and D.H.; funding acquisition, D.H.; investigation, H.L.; methodology, H.L. and C.S.; project administration, Z.Z. and D.H.; resources, D.H.; software, H.L. and B.H.; supervision, Y.H., Z.Z., D.H. and C.S.; validation, D.H.; visualization, H.L. and B.H.; writingoriginal draft, H.L. and B.H.; writing-review and editing, Y.H., Z.Z., D.H. and C.S. All authors have read and agreed to the published version of the manuscript.

Funding: This research was funded by National Natural Science Foundation of China, grant number 31970484; National Natural Science Foundation of China, grant number 31770160; Program of Ministry of Science and Technology of China, grant number 2018FY100405 and National Natural Science Foundation of Chongqing, grant number cstc2018jcyjAX0382.

Institutional Review Board Statement: Not applicable.

Informed Consent Statement: Not applicable.

Data Availability Statement: All mitogenomic sequences in this study are available in the GenBank database (https:/ / www.ncbi.nlm.nih.gov/nuccore), and accession numbers of mitogenomes are available in the Supplementary Material (Table S1)

Conflicts of Interest: The authors declare no conflict of interest.

\section{References}

1. Michener, C.D. The Bees of the World, 2nd ed.; The Johns Hopkins University Press: Baltimore, MD, USA, 2007; pp. 434-543, ISBN 9780801885730.

2. Danforth, B.N.; Cardinal, S.; Praz, C.; Almeida, E.A.B.; Michez, D. The Impact of Molecular Data on Our Understanding of Bee Phylogeny and Evolution. Annu. Rev. Entomol. 2013, 58, 57-78. [CrossRef] [PubMed]

3. Ascher, J.S.; Pickering, J. Discover Life Bee Species Guide and World Checklist (Hymenoptera: Apoidea: Anthophila). Draft-50. 2018. Available online: http://www.discoverlife.org/mp/20q?guide=Apoidea_species (accessed on 31 March 2018).

4. Litman, J.R.; Danforth, B.N.; Eardley, C.D.; Praz, C.J. Why do leafcutter bees cut leaves? New insights into the early evolution of bees. Proc. R. Soc. B. 2011, 278, 3593-3600. [CrossRef] [PubMed]

5. De Sabino, W.O.; Antonini, Y. Nest Architecture, Life Cycle, and Natural Enemies of the Neotropical Leafcutting Bee Megachile (Moureapis) maculata (Hymenoptera: Megachilidae) in a Montane Forest. Apidologie 2017, 48, 450-460.

6. Gonzalez, V.H.; Griswold, T.; Praz, C.J.; Danforth, B.N. Phylogeny of the Bee Family Megachilidae (Hymenoptera: Apoidea) Based on Adult Morphology. Syst. Entomol. 2012, 37, 261-286. [CrossRef]

7. Pitts-Singer, T.L.; Cane, J.H. The Alfalfa Leaf-Cutting Bee, Megachile rotundata: The World's Most Intensively Managed Solitary Bee. Annu. Rev. Entomol. 2011, 56, 221-237. [CrossRef] [PubMed]

8. Kraemer, M.E.; Favi, F.D. Flower Phenology and Pollen Choice of Osmia lignaria (Hymenoptera: Megachilidae) in Central Virginia. Environ. Entomol. 2005, 34, 1593-1605. [CrossRef]

9. Vicens, N.; Bosch, J. Weather-Dependent Pollinator Activity in an Apple Orchard, with Special Reference to Osmia cornuta and Apis mellifera (Hymenoptera: Megachilidae and Apidae). Environ. Entomol. 2000, 29, 413-420. [CrossRef]

10. Soh, E.J.Y.; Soh, Z.W.W.; Chui, S.X.; Ascher, J.S. The Bee Tribe Anthidiini in Singapore (Anthophila: Megachilidae: Anthidiini) with Notes on the Regional Fauna. Nat. Singap. 2016, 9, 49-62.

11. Baker, D.B. A Review of Asian Species of Genus Euaspis Gerstäcker (Hymenoptera: Apoidea: Megachilidae). Zool. Meded. 1995, 69, 281-302.

12. Nadimi, A.; Talebi, A.A.; Fathipour, Y. A Preliminary Study of the Cleptoparasitic Bees of the Genus Coelioxys (Hymenoptera: Megachilidae) in Northern Iran, with Six New Records. J. Crop Prot. 2013, 2, 271-283.

13. Filho, L.C.; Garófalo, C.A. Nesting Biology of Megachile (Chrysosarus) guaranitica and High Mortality Caused by Its Cleptoparasite Coelioxys bertonii (Hymenoptera: Megachilidae) in Brazil. Austral Entomol. 2015, 55, 25-31. [CrossRef]

14. Roig-Alsina, A.; Michener, C.D. Studies of the Phylogeny and Classification of Long-Tongued Bees (Hymenoptera: Apoidea). Kans. Univ. Sci. Bull. 1993, 55, 124-162.

15. Wu, Y.R. Fauna Sinica: Insecta, Volume 44: Hymenoptera: Megachilidae; Science Press: Beijing, China, 2006; pp. 2-3, ISBN 7-03-016332-X.

16. Engel, M.S. A Monograph of the Baltic Amber Bees and Evolution of the Apoidea (Hymenoptera). Bull. Am. Mus. Nat. Hist. 2001, 259, 1-192. [CrossRef]

17. Praz, C.J.; Müller, A.; Danforth, B.N.; Griswold, T.L.; Widmer, A.; Dorn, S. Phylogeny and Biogeography of Bees of the Tribe Osmiini (Hymenoptera: Megachilidae). Mol. Phylogenet. Evol. 2008, 49, 185-197. [CrossRef] [PubMed]

18. Kahnt, B.; Gerth, M.; Paxton, R.J.; Bleidorn, C.; Husemann, M. The Complete Mitochondrial Genome of the Endemic and Highly Specialized South African Bee Species Rediviva intermixta (Hymenoptera: Melittidae), with a Comparison with Other Bee Mitogenomes. Biol. J. Linn. Soc. 2015, 116, 940-953. [CrossRef] 
19. Cameron, S.L. Insect Mitochondrial Genomics: Implications for Evolution and Phylogeny. Annu. Rev. Entomol. 2014, 59, 95-117. [CrossRef]

20. Mao, M.; Gibson, T.; Dowton, M. Higher-Level Phylogeny of the Hymenoptera Inferred from Mitochondrial Genomes. Mol. Phylogenet. Evol. 2015, 84, 34-43. [CrossRef]

21. Song, S.N.; Tang, P.; Wei, S.J.; Chen, X.X. Comparative and Phylogenetic Analysis of the Mitochondrial Genomes in Basal Hymenopterans. Sci. Rep. 2016, 6, 1-11. [CrossRef]

22. Li, Q.; Yang, L.X.; Xiang, D.B.; Wan, Y.; Wu, Q.; Huang, W.L.; Zhao, G. The Complete Mitochondrial Genomes of Two Model Ectomycorrhizal Fungi (Laccaria): Features, Intron Dynamics and Phylogenetic Implications. Int. J. Biol. Macromol. 2020, 145, 974-984. [CrossRef]

23. Song, F.; Li, H.; Jiang, P.; Zhou, X.; Liu, J.; Sun, C.; Vogler, A.P.; Cai, W. Capturing the Phylogeny of Holometabola with Mitochondrial Genome Data and Bayesian Site-Heterogeneous Mixture Models. Genome Biol. Evol. 2016, 8, 1411-1426. [CrossRef]

24. Liu, Y.; Li, H.; Song, F.; Zhao, Y.; Wilson, J.J.; Cai, W. Higher-Level Phylogeny and Evolutionary History of Pentatomomorpha (Hemiptera: Heteroptera) Inferred from Mitochondrial Genome Sequences. Syst. Entomol. 2019, 44, 810-819. [CrossRef]

25. Du, Z.; Hasegawa, H.; Cooley, J.R.; Simon, C.; Jin, Y.; Cai, W.; Sota, T.; Li, H. Mitochondrial Genomics Reveals Shared Phylogeographic Patterns and Demographic History among Three Periodical Cicada Species Groups. Mol. Biol. Evol. 2019, 36, 1187-1200. [CrossRef] [PubMed]

26. Dowton, M.; Cameron, S.L.; Dowavic, J.I.; Austin, A.D.; Whiting, M.F. Characterization of 67 Mitochondrial tRNA Gene Rearrangements in the Hymenoptera Suggests that Mitochondrial tRNA Gene Position Is Selectively Neutral. Mol. Biol. Evol. 2009, 26, 1607-1617. [CrossRef] [PubMed]

27. Song, F.; Li, H.; Shao, R.; Shi, A.; Bai, X.; Zheng, X.; Heiss, E.; Cai, W. Rearrangement of Mitochondrial tRNA Genes in Flat Bugs (Hemiptera: Aradidae). Sci. Rep. 2016, 6, 25725. [CrossRef] [PubMed]

28. Zhang, Y.; Su, T.J.; He, B.; Gu, P.; Huang, D.Y.; Zhu, C.D. Sequencing and Characterization of the Megachile sculpturalis (Hymenoptera: Megachilidae) Mitochondrial Genome. Mitochondrial DNA Part A 2015, 28, 309-311. [CrossRef]

29. Huang, D.Y.; Su, T.J.; He, B.; Gu, P.; Liang, A.P.; Zhu, C.D. Sequencing and Characterization of the Megachile strupigera (Hymenoptera: Megachilidae) Mitochondrial Genome. Mitochondrial DNA Part B 2016, 1, 309-311. [CrossRef]

30. Zheng, B.Y.; Cao, L.J.; Tang, P.; van Achterberg, K.; Hoffmann, A.A.; Chen, H.Y.; Chen, X.X.; Wei, S.J. Gene Arrangement and Sequence of Mitochondrial Genomes Yield Insights Into the Phylogeny and Evolution of Bees and Sphecid Wasps (Hymenoptera: Apoidea). Mol. Phylogenet. Evol. 2018, 124,1-9. [CrossRef]

31. Hahn, C.; Bachmann, L.; Chevreux, B. Reconstructing Mitochondrial Genomes Directly from Genomic Next-Generation Sequencing Reads-A Baiting and Iterative Mapping Approach. Nucleic Acids Res. 2013, 41, e129. [CrossRef]

32. Bernt, M.; Donath, A.; Jühling, F.; Externbrink, F.; Florentz, C.; Fritzsch, G.; Pütz, J.; Middendorf, M.; Stadler, P.F. MITOS: Improved de Novo Metazoan Mitochondrial Genome Annotation. Mol. Phylogenet. Evol. 2013, 69, 313-319. [CrossRef]

33. Laslett, D.; Canback, B. ARWEN: A Program to Detect tRNA Genes in Metazoan Mitochondrial Nucleotide Sequences. Bioinformatics 2008, 24, 172-175. [CrossRef]

34. Lowe, T.M.; Chan, P.P. tRNAscan-SE Online: Integrating Search and Context for Analysis of Transfer RNA Genes. Nucleic Acids Res. 2016, 44, W54-W57. [CrossRef] [PubMed]

35. Rose, R.; Golosova, O.; Sukhomlinov, D.; Tiunov, A.; Prosperi, M. Flexible Design of Multiple Metagenomics Classification Pipelines with UGENE. Bioinformatics 2019, 35, 1963-1965. [CrossRef]

36. Gillespie, J.J.; Johnston, J.S.; Cannone, J.J.; Gutell, R.R. Characteristics of the Nuclear (18S, 5.8S, 28S and 5S) and Mitochondrial (12S and 16S) rRNA Genes of Apis mellifera (Insecta: Hymenoptera): Structure, Organization, and Retrotransposable Elements. Insect Mol. Biol. 2006, 15, 657-686. [CrossRef] [PubMed]

37. Wei, S.J.; Tang, P.; Zheng, L.H.; Shi, M.; Chen, X.X. The Complete Mitochondrial Genome of Evania appendigaster (Hymenoptera: Evaniidae) Has Low A + T Content and a Long Intergenic Spacer between atp8 and atp6. Mol. Biol. Rep. 2010, 37, 1931-1942. [CrossRef] [PubMed]

38. Su, T.J.; He, B.; Li, K.; Liang, A.P. Comparative Analysis of the Mitochondrial Genomes of Oriental Spittlebug Trible Cosmoscartini: Insights Into the Relationships among Closely Related Taxa. BMC Genom. 2018, 19, 1-13. [CrossRef]

39. He, B.; Su, T.J.; Niu, Z.Q.; Zhou, Z.Y.; Gu, Z.Y.; Huang, D.Y. Characterization of Mitochondrial Genomes of Three Andrena Bees (Apoidea: Andrenidae) and Insights Into the Phylogenetics. Int. J. Biol. Macromol. 2019, 127, 118-125. [CrossRef] [PubMed]

40. Cannone, J.J.; Subramanian, S.; Schnare, M.N.; Collett, J.R.; D’Souza, L.M.; Du, Y.; Feng, B.; Lin, N.; Madabusi, L.V.; Müller, K.M.; et al. The Comparative RNA Web (CRW) Site: An Online Database of Comparative Sequence and Structure Information for Ribosomal, Intron, and Other RNAs. BMC Bioinform. 2002, 3, 2.

41. Reuter, J.S.; Mathews, D.H. RNA Structure: Software for RNA Secondary Structure Prediction and Analysis. BMC Bioinform. 2010, 11, 1-9. [CrossRef]

42. Alikhan, N.F.; Petty, N.K.; Zakour, N.L.B.; Beatson, S.A. BLAST Ring Image Generator (BRIG): Simple Prokaryote Genome Comparisons. BMC Genom. 2011, 12, 402. [CrossRef]

43. Zhang, D.; Gao, F.; Jakovlić, I.; Zou, H.; Zhang, J.; Li, W.X.; Wang, G.T. PhyloSuite: An Integrated and Scalable Desktop Platform for Streamlined Molecular Sequence Data Management and Evolutionary Phylogenetics Studies. Mol. Ecol. Res. 2020, 20, 348-355. [CrossRef] 
44. Librado, P.; Rozas, J. DnaSP v5: A Software for Comprehensive Analysis of DNA Polymorphism Data. Bioinformatics 2009, 25, 1451-1452. [CrossRef]

45. Beier, S.; Thiel, T.; Münch, T.; Scholz, U.; Mascher, M. MISA-Web: A Web Server for Microsatellite Prediction. Bioinformatics 2017, 33, 2583-2585. [CrossRef]

46. Xia, X. DAMBE7: New and Improved Tools for Data Analysis in Molecular Biology and Evolution. Mol. Biol. Evol. 2018, 35, 1550-1552. [CrossRef] [PubMed]

47. Lanfear, R.; Frandsen, P.B.; Wright, A.M.; Senfeld, T.; Calcott, B. PartitionFinder 2: New Methods for Selecting Partitioned Models of Evolution for Molecular and Morphological Phylogenetic Analyses. Mol. Biol. Evol. 2016, 34, 772-773. [CrossRef] [PubMed]

48. Bernt, M.; Merkle, D.; Ramsch, K.; Fritzsch, G.; Perseke, M.; Bernhard, D.; Schlegel, M.; Stadler, P.F.; Middendorf, M. CREx: Inferring Genomic Rearrangements Based on Common Intervals. Bioinformatics 2007, 23, 2957-2958. [CrossRef]

49. Rambaut, A.; Drummond, A.J.; Xie, D.; Baele, G.; Suchard, M.A. Posterior Summarisation in Bayesian Phylogenetics Using Tracer 1.7. Syst. Biol. 2018, 67, 901. [CrossRef] [PubMed]

50. Letunic, I.; Bork, P. Interactive Tree of Life (iTOL) v3: An Online Tool for the Display and Annotation of Phylogenetic and Other Trees. Nucleic Acids Res. 2016, 44, W242-W245. [CrossRef] [PubMed]

51. Lu, H.H.; Huang, D.Y. The Complete Mitogenome of Habropoda rodoszkowskii (Hymenoptera: Apidae) and Phylogenetic Analysis. Mitochondrial DNA Part B 2020, 5, 2350-2351. [CrossRef]

52. He, B.; Su, T.J.; Wu, Y.P.; Xu, J.S.; Huang, D.Y. Phylogenetic Analysis of the Mitochondrial Genomes in Bees (Hymenoptera: Apoidea: Anthophila). PLoS ONE 2018, 13, e0202187. [CrossRef]

53. Ojala, D.; Montoya, J.; Attardi, G. tRNA Punctuation Model of RNA Processing in Human Mitochondria. Nature 1981, 290, 470-474. [CrossRef]

54. Li, H.Y.; Lu, H.H.; Huang, S.G.; Fan, X.D.; Luo, A.C.; Huang, D.Y. The Complete Mitogenome of Nomia chalybeata (Hymenoptera: Halictidae) and Phylogenetic Analysis. Mitochondrial DNA Part B 2020, 5, 2850-2851. [CrossRef]

55. Lavrov, D.V.; Brown, W.M.; Boore, J.L. A Novel Type of RNA Editing Occurs in the Mitochondrial tRNAs of the Centipede Lithobius forficatus. Proc. Natl. Acad. Sci. USA 2000, 97, 13738-13742. [CrossRef] [PubMed]

56. Cameron, S.L.; Whiting, M.F. The Complete Mitochondrial Genome of the Tobacco Hornworm, Manduca sexta, (Insecta: Lepidoptera: Sphingidae), and an Examination of Mitochondrial Gene Variability within Butterflies and Moths. Gene 2008, 408, 112-123. [CrossRef] [PubMed]

57. Shao, L.L.; Huang, D.Y.; Sun, X.Y.; Hao, J.S.; Cheng, C.H.; Zhang, W.; Yang, Q. Complete Mitochondrial Genome Sequence of Cheirotonus jansoni (Coleoptera: Scarabaeidae). Genet. Mol. Res. 2014, 13, 1047-1058. [CrossRef] [PubMed]

58. Su, T.J.; Liang, A.P. Characterization of the Complete Mitochondrial Genome of Phymatostetha huangshanensis (Hemiptera: Cercopidae) and Phylogenetic Analysis. Int. J. Biol. Macromol. 2018, 119, 60-69. [CrossRef]

59. Park, J.K.; Kim, K.H.; Kang, S.; Kim, W.; Eom, K.S.; Littlewood, D.T. A Common Origin of Complex Life Cycles in Parasitic Flatworms: Evidence from the Complete Mitochondrial Genome of Microcotyle sebastis (Monogenea: Platyhelminthes). BMC Evol. Biol. 2007, 7, 11. [CrossRef]

60. Zhang, D.; Li, W.X.; Zou, H.; Wu, S.G.; Li, M.; Jakovlić, I.; Zhang, J.; Chen, R.; Wang, G.T. Mitochondrial Genomes and 28S rDNA Contradict the Proposed Obsoletion of the Order Tetraonchidea (Platyhelminthes: Monogenea). Int. J. Biol. Macromol. 2019, 143, 891-901. [CrossRef]

61. Le, T.H.; Blair, D.; McManus, D.P. Mitochondrial Genomes of Parasitic Flatworms. Trends Parasitol. 2002, 18, 206-213. [CrossRef]

62. Fumagalli, L.; Taberlet, P.; Favre, L.; Hausser, J. Origin and Evolution of Homologous Repeated Sequences in the Mitochondrial DNA Control Region of Shrews. Mol. Biol. Evol. 1996, 13, 31-46. [CrossRef]

63. Zhang, R.Y.; Li, J.; Geng, S.; Yang, J.; Zhang, X.; An, Y.X.; Li, C.; Cui, H.R.; Li, X.Y.; Wang, Y.Y. The First Mitochondrial Genome for Phaudidae (Lepidoptera) with Phylogenetic Analyses of Zygaenoidea. Int. J. Biol. Macromol. 2020, 149, 951-961. [CrossRef]

64. Dowton, M.; Austin, A.D. Evolutionary Dynamics of a Mitochondrial Rearrangement "Hot Spot" in the Hymenoptera. Mol. Biol. Evol. 1999, 16, 298-309. [CrossRef] [PubMed]

65. Dowton, M.; Castro, L.R.; Campbell, S.L.; Bargon, S.D.; Austin, A.D. Frequent Mitochondrial Gene Rearrangements at the Hymenopteran nad3-nad5 Junction. J. Mol. Evol. 2003, 56, 517-526. [CrossRef] [PubMed]

66. Chen, L.; Chen, P.Y.; Xue, X.F.; Hua, H.Q.; Li, Y.X.; Zhang, F.; Wei, S.J. Extensive Gene Rearrangements in the Mitochondrial Genomes of Two Egg Parasitoids, Trichogramma japonicum and Trichogramma ostriniae (Hymenoptera: Chalcidoidea: Trichogrammatidae). Sci. Rep. 2018, 8, 1-11. [CrossRef] [PubMed]

67. Pureum, N.; Wook, J.K.; Jun-Ho, S.; Inkyu, P.; Goya, C.; Byeong, C.M. Rapid and Simple Species Identification of Cicada Exuviae Using COI-Based SCAR Assay. Insects 2020, 11, 168.

68. Elaine, F.; Alexandre, R.Z.; Paulo, C.R.; João, P.; Naldi, S.; Rute, B.; Benjamin, P.O.; Maria, C.A. Conserved Numts Mask a Highly Divergent Mitochondrial-COI Gene in a Species Complex of Australian Stingless Bees Tetragonula (Hymenoptera: Apidae). Mitochondrial DNA Part A 2019, 30, 806-817.

69. Goldstein, D.B.; Linares, A.R.; Cavalli-Sforza, L.L.; Feldman, M.W. An Evaluation of Genetic Distances for Use with Microsatellite Loci. Genetics 1995, 139, 463-471.

70. Cameron, S.L.; Johnson, K.P.; Whiting, M.F. The Mitochondrial Genome of the Screamer Louse Bothriometopus (Phthiraptera: Ischnocera): Effects of Extensive Gene Rearrangements on the Evolution of the Genome. J. Mol. Evol. 2007, 65, 589-604. [CrossRef] 
71. Yang, X.S.; Cameron, S.L.; Lees, D.C.; Xue, D.Y.; Han, H.X. A Mitochondrial Genome Phylogeny of Owlet Moths (Lepidoptera: Noctuoidea), and Examination of the Utility of Mitochondrial Genomes for Lepidopteran Phylogenetics. Mol. Phylogenet. Evol. 2015, 85, 230-237. [CrossRef]

72. Cameron, S.L.; Lo, N.; Bourguignon, T.; Svenson, G.J.; Evans, T.A. A Mitochondrial Genome Phylogeny of Termites (Blattodea: Termitoidae): Robust Support for Interfamilial Relationships and Molecular Synapomorphies Define Major Clades. Mol. Phylogenet. Evol. 2012, 65, 162-173. [CrossRef]

73. Nelson, L.A.; Lambkin, C.L.; Batterham, P.J.; Wallman, J.F.; Dowton, M.; Whiting, M.F.; Yeatesa, D.K.; Camerong, S.L. Beyond Barcoding: A Mitochondrial Genomics Approach to Molecular Phylogenetics and Diagnostics of Blowflies (Diptera: Calliphoridae). Gene 2012, 511, 131-142. [CrossRef]

74. Yang, X.S.; Xue, D.Y.; Han, H.X. The Complete Mitochondrial Genome of Biston panterinaria (Lepidoptera: Geometridae), with Phylogenetic Utility of Mitochondrial Genome in the Lepidoptera. Gene 2013, 515, 349-358. [CrossRef] [PubMed]

75. Mao, M.; Dowton, M. Complete Mitochondrial Genomes of Ceratobaeus sp. and Idris sp. (Hymenoptera: Scelionidae): Shared Gene Rearrangements as Potential Phylogenetic Markers at the Tribal Level. Mol. Biol. Rep. 2014, 41, 6419-6427. [CrossRef] [PubMed]

76. Aydemir, M.N.; Korkmaz, E.M. Comparative Mitogenomics of Hymenoptera Reveals Evolutionary Differences in Structure and Composition. Int. J. Biol. Macromol. 2019, 144, 460-472. [CrossRef] [PubMed]

77. Brady, S.G.; Litman, J.R.; Danforth, B.N. Rooting Phylogenies Using Gene Duplications: An Empirical Example from the Bees (Apoidea). Mol. Phylogenet. Evol. 2011, 60, 295-304. [CrossRef]

78. Dellicour, S.; Lecocq, T.; Kuhlmann, M.; Mardulyn, P.; Michez, D. Molecular Phylogeny, Biogeography, and Host Plant Shifts in the Bee Genus Melitta (Hymenoptera: Anthophila). Mol. Phylogenet. Evol. 2014, 70, 412-419. [CrossRef] [PubMed]

79. Debevec, A.H.; Cardinal, S.; Danforth, B.N. Identifying the Sister Group to the Bees: A Molecular Phylogeny of Aculeata with an Emphasison the Superfamily Apoidea. Zool. Scr. 2012, 41, 527-535. [CrossRef]

80. Hedtke, S.M.; Patiny, S.; Danforth, B.N. The Bee Tree of Life: A Supermatrix Approach to Apoid Phylogeny and Biogeography. BMC Evol. Biol. 2013, 13, 138. [CrossRef]

81. Peters, R.S.; Krogmann, L.; Mayer, C.; Donath, A.; Gunkel, S.; Meusemann, K.; Kozlov, A.; Podsiadlowski, L.; Petersen, M.; Lanfear, R.; et al. Evolutionary History of the Hymenoptera. Curr. Biol. 2017, 27, 1013-1018. [CrossRef]

82. Branstetter, M.G.; Danforth, B.N.; Pitts, J.P.; Faircloth, B.C.; Ward, P.S.; Buffington, M.L.; Gates, M.W.; Kula, R.R.; Brady, S.G. Phylogenomic Insights Into the Evolution of Stinging Wasps and the Origins of Ants and Bees. Curr. Biol. 2017, 27, 1019-1025. [CrossRef]

83. Sann, M.; Niehuis, O.; Peters, R.S.; Mayer, C.; Kozlov, A.; Podsiadlowski, L.; Bank, S.; Meusemann, K.; Misof, B.; Bleidorn, C.; et al. Phylogenomic Analysis of Apoidea Sheds New Light on the Sister Group of Bees. BMC Evol. Biol. 2018, 18, 71. [CrossRef]

84. Litman, J.R.; Praz, C.J.; Danforth, B.N.; Griswold, T.L.; Cardinal, S. Origins, evolution, and diversification of cleptoparasitic lineages in long-tongued bees. Evolution 2013, 67, 2982-2998. [CrossRef] [PubMed]

85. Litman, J.R.; Griswold, T.; Danforth, B.N. Phylogenetic systematics and a revised generic classification of anthidiine bees (Hymenoptera: Megachilidae). Mol. Phylogenet. Evol. 2016, 100, 183-198. [CrossRef] [PubMed] 